\title{
The annual cycle of fossil-fuel carbon dioxide emissions in the United States
}

\author{
By T. J. BLASING ${ }^{1 *}$, C. T. BRONIAK ${ }^{2}$ and G. MARLAND ${ }^{1},{ }^{1}$ Environmental Sciences Division, Oak \\ Ridge National Laboratory, Oak Ridge, TN 37831-6335, USA; ${ }^{2}$ Department of Agricultural and Resource Economics, \\ Oregon State University, Corvallis OR 97331, USA
}

(Manuscript received 9 February 2004; in final form 22 September 2004)

\begin{abstract}
Time-series of estimated monthly carbon dioxide emissions from consumption of coal, petroleum and natural gas in the United States from 1981 to 2002 have been derived from energy consumption data. The data series for coal and natural gas each reveal a consistent seasonal pattern, with a winter peak for gas and two peaks (summer and winter) for coal. The annual cycle of total emissions has an amplitude of about $20 \mathrm{Tg}-\mathrm{C}$, and is dominated by $\mathrm{CO}_{2}$ released from consumption of natural gas. Summation of the monthly estimates to obtain annual values reveals good agreement with other estimates of $\mathrm{CO}_{2}$ emissions. The varying proportions of $\mathrm{CO}_{2}$ emitted from each fuel type over the course of a year lead to an annual cycle in the carbon isotope ratio $\left(\delta^{13} \mathrm{C}\right)$, with a range of about $2 \%$. These monthly carbon emissions estimates should be helpful in understanding the carbon cycle by providing (1) monthly/seasonal input for carbon cycle models, (2) estimates of the annual cycle of the ${ }^{13} \mathrm{C}$ isotope ratio in fossil-fuel $\mathrm{CO}_{2}$ emissions and (3) data at fine enough time intervals to investigate effects of seasonal climate variations and changes in seasonally dependent use patterns of certain appliances (e.g. air conditioners) on fossil-fuel carbon emissions.
\end{abstract}

\section{Introduction}

The growth, and superimposed annual cycle, of atmospheric $\mathrm{CO}_{2}$ concentration has been measured at the South Pole and at Mauna Loa Observatory, Hawaii, since the late 1950s (Keeling and Whorf, 2003), and at many other stations worldwide for shorter time periods (e.g. Steele et al., 2002). However, relatively less is known about the sources and sinks of atmospheric $\mathrm{CO}_{2}$ that lead to these observed changes in concentration. One important component of the flux of $\mathrm{CO}_{2}$ to and from the atmosphere is the combustion of fossil fuels. A time-series of annual emissions of $\mathrm{CO}_{2}$ from fossil-fuel combustion since the beginning of the fossil-fuel era is available (Marland et al., 2003) but a time-series of monthly fossil-fuel emissions should provide a foundation to better understand the seasonal progression of physical and biological processes that influence, and are influenced by, the atmospheric $\mathrm{CO}_{2}$ concentration, thus facilitating investigations of global carbon cycling.

The difficulty in unravelling the details of the global carbon cycle and in developing policies for confronting global climate change, without better understanding of the sources and sinks of the two most important greenhouse gases $\left(\mathrm{CO}_{2}\right.$ and $\left.\mathrm{CH}_{4}\right)$, has prompted creation of an integrated scientific initiative, The

\footnotetext{
${ }^{*}$ Corresponding author. e-mail: blasingtj@ornl.gov
}

North American Carbon Program (NACP) (Wofsy and Harris, 2002). The NACP is designed to improve understanding of the $\mathrm{CO}_{2}$ fluxes, and thus to improve understanding of the outcomes of actions to affect the carbon cycle. The NACP puts improved spatial and temporal resolution of $\mathrm{CO}_{2}$ emissions inventories as one of its objectives.

The importance of knowing the annual cycle of carbon dioxide emissions in addition to the annual totals has long been realized. Rotty (1987) estimated the annual cycle for global fossil-fuel emissions for 1982 by allocating the annual total emissions to each calendar month according to monthly energy use statistics, but the data available for this exercise put heavy demands on approximations and proxy data. In this paper we describe the development of a time-series of monthly $\mathrm{CO}_{2}$ emissions estimates from fossil-fuel use in the United States (US) that covers the period 1981 to 2002 .

Additionally, monthly (or seasonal) emissions estimates can be compared with monthly (or seasonal) anomalies in meteorological variables (e.g. temperature) to identify influences of climate on fossil-fuel $\mathrm{CO}_{2}$ emissions. The convolution of differing climatic influences on energy consumption over the course of a year precludes the use of annual data to specify such influences; for example warm winters decrease energy requirements for heating but warm summers increase energy requirements for cooling, so the numerical integration of these effects over the course of a warm year would require accounting for these 
opposing seasonal influences. Thus, the lack of carbon emissions data at subannual timescales precludes the identification of climatic effects on carbon emissions. Sale and Hadley (2002) have shown, for example, that the effect of hydroelectric power on $\mathrm{CO}_{2}$ emissions depends not only on the amount of hydropower used, but also on when and how it is used. Human interactions make a large and growing contribution to the global carbon cycle and understanding of these interactions requires data at spatial and temporal scales finer than the national and annual data often used now for carbon cycle studies.

The results presented here are for the US only; monthly $\mathrm{CO}_{2}$ emissions at the global scale will eventually have to be estimated before some of the applications of monthly emissions data can be realized. This global-scale effort is under way as a joint effort between the University of North Dakota and Oak Ridge National Laboratory. Because most of the world's fossil-fuel $\mathrm{CO}_{2}$ comes from mid-latitude, Northern Hemisphere industrialized nations, such as the US (which has been responsible for approximately $23 \%$ of global emissions during recent years), US data are expected to give an initial indication of the global pattern.

In the following section of this paper we outline and describe the requisite data to establish monthly $\mathrm{CO}_{2}$ emissions data for the US. In Section 3 we summarize our monthly emissions estimates, and in Section 4 we calculate annual sums and compare the results with other estimates of annual $\mathrm{CO}_{2}$ emissions for the US. We also examine the pioneering attempt of Rotty (1987) to estimate monthly carbon emissions for one year (1982) and we compare his results with ours. In Section 5 we discuss some possible applications of the monthly emissions data, broken down by fuel type (coal, oil and natural gas), to investigate phenomena which could not be investigated with annual data only. These include: (1) investigation of some fine-scale details of the carbon cycle, (2) calculation of the annual cycle of the ${ }^{13} \mathrm{C}$ signature in fossil-fuel $\mathrm{CO}_{2}$ emissions and (3) investigation of the relationships of carbon emissions to spatial patterns of seasonal climate variations, and to seasonally dependent uses of fossil-fuel powered machines (e.g. air conditioners). Section 6 gives a summary of the paper.

\section{Data and methods}

The basic data we used to construct the monthly time-series of $\mathrm{CO}_{2}$ emissions were consumption data for coal, petroleum and natural gas which were provided electronically by the Energy Information Administration (EIA), US Department of Energy (DOE). These data are also available in hard copy in Monthly Energy Review, a publication of the EIA. Monthly data for coal and natural gas go back to 1973 but data for petroleum and petroleum products go back only to 1981 , so the $\mathrm{CO}_{2}$ emissions data set could be completed only back to 1981 . Data were provided in bulk units (i.e. tons of coal, barrels of oil and cubic feet of natural gas). The bulk data were multiplied by the appropriate mean heat content of each fuel type, in units of Btu per bulk unit, to arrive at values of energy (in Btu) realized from the oxidation of the fuel. These energy values were then multiplied by the appropriate carbon coefficients, in units of grams of carbon per Btu of energy realized, to arrive at carbon oxidized. Because about 0.5 to $1.0 \%$ of the carbon is not oxidized during combustion, the results were multiplied by either 0.995 (for natural gas) or 0.99 (for coal and petroleum), as per Table A-14 of EPA (2002), to arrive at final values of carbon emitted as $\mathrm{CO}_{2}$.

The mean heat content of some products changes with time, depending on such things as the composition of coal, the blend of primary ingredients in certain petroleum products and impurities in natural gas. We used values given in Appendix A of recent issues of Monthly Energy Review (e.g. EIA, 2003, p. 157). The carbon coefficients we used can be found in EIA (2002) (especially Appendix B) or EPA (2002) (especially Annex A and Annex B). Like heat contents, some carbon coefficients change slightly over time. Annual values back to 1990 are available in EIA (2002) and EPA (2002), values back to 1984 can be found in EIA (1995) (Table A1). The 1984 values were used for estimating $\mathrm{CO}_{2}$ emissions from 1981-83. In all cases the US data sources give heat content in terms of the higher heating value of the respective fuels; that is, the heating values are determined at constant volume.

Carbon dioxide emissions estimates produced here include allowance for oxidation of fossil-fuel products even if those products are not used as fuels, whereas earlier estimates (Marland et al., 2003) were based only on fuel uses. The simple assumption suggested by the IPCC (1997), and adopted here, is that the amount of carbon in a non-fuel product oxidized during any month is equal to a constant fraction of the current consumption of that product. In other words, consumption exceeds oxidation of the product during the given month so that there is an increase in carbon stocks that can be estimated as a constant fraction of the rate of consumption.

The fraction of carbon oxidized that we used for these petroleum products is taken from Appendix B of EPA (2002), and is applicable to the US. For example, we have allowed for $100 \%$ oxidation of paint thinner, $91 \%$ of lubricants and none of asphalt. The result of including oxidized fractions of non-fuel products is an increase in the overall accuracy of our emissions estimates, but some errors remain in the temporal allocation of these $\mathrm{CO}_{2}$ emissions. Marland and Marland (2002) showed that this internationally used approach for estimating emissions from non-fuel uses is, at best, a rough approximation, but the method does acknowledge that some oxidation is occurring.

There is a similar small effect related to the production of carbon monoxide (CO) during fuel combustion. Our assumption is that $\mathrm{CO}$ is soon oxidized to $\mathrm{CO}_{2}$ in the atmosphere and that the intermediate step can be ignored with the assumption that all of the carbon soon ends up in $\mathrm{CO}_{2}$. If the rate of $\mathrm{CO}$ production is changing rapidly with time, there could be some small lag between fuel consumption and $\mathrm{CO}_{2}$ production. 
In fact, estimates of $\mathrm{CO}_{2}$ emissions at fine temporal and spatial scales raise fundamental questions about the definition of "consumption" as reported in basic energy data. Although consumption data must ultimately be based on fuel-transaction data (e.g. local gasoline distributors' records of deliveries to retailers), they represent an attempt to estimate actual final consumption during specified time intervals (individual months for this study).

We note again that the estimates of monthly $\mathrm{CO}_{2}$ emissions derived here are based on fuel consumption data as reported by the US DOE/EIA. By contrast, the estimates of annual $\mathrm{CO}_{2}$ emissions produced by Marland et al. (2003) are based on data on "apparent consumption" from the United Nations Statistical Office. National apparent consumption refers to production plus imports less the total of exports, increases in stocks, and fuel loaded for use in international commerce. In general "consumption" will not be exactly equal to "apparent consumption". The DOE/EIA data set includes a specific entry, labelled "balancing item" (the International Energy Agency calls it "statistical difference"). This balancing item represents the difference between the sum of the components of fuel supply (i.e. apparent consumption) and the sum of the components of fuel consumption. The difference may be due to fuel lost, unaccounted consumption or reporting problems. Reporting problems include variations in accounting and billing cycles, differences due to volume changes as a function of temperature and pressure, etc. For example, for US natural gas data from 1973 to 1999 this balancing item is a negative number in all except 2 years, so that apparent consumption is generally larger than measured consumption. The difference varies from $+1.0 \%$ to $-4.8 \%$ and averages $-2.0 \%$ of consumption, possibly influenced by some loss of product between the supply and demand sides.

Our current results do not include carbon oxidized from calcining limestone for cement manufacture or from gas flaring. These sources, combined, are less than $1 \%$ of annual $\mathrm{CO}_{2}$ from the US. Annual emissions estimates for these sources are available in Marland et al. (2003), but data to estimate how these vary throughout the year are limited.

Some indication of data quality can be obtained by comparison with other data sets, but this is limited by the fact that ultimately all estimates rely on the same collections of energy data and the comparisons in large measure reflect the quality of data processing. In general we are able to discover where and why our estimates differ from those of others. Marland and Rotty (1984) suggested that their estimates of global $\mathrm{CO}_{2}$ emissions had an absolute uncertainty of 6 to $10 \%$, it would be $6 \%$ if the uncertainties for the individual fuels were independent. For our monthly estimates uncertainty arises from: (1) basic energy statistics, (2) conversion of energy data to $\mathrm{CO}_{2}$ emissions and (3) characterization of the fractions of fuel use that do not result in current-month oxidation. The latter can be because of inefficient combustion, because some petrochemicals go into long-lived products or because the fuel "consumption" data do not accurately reflect the actual time of fuel oxidation. Marland et al. (1995) have col- lected enough data on the carbon content of coals to provide a statistical estimate for the standard error of the mean-about $2 \%$ - and comparable values should apply for the other fuels. It is difficult to come up with rigorous estimates for the other elements of uncertainty, but our judgement is that the final monthly values for the US have an uncertainty on the order of 3-4\%, with about half of the error (about $2 \%$ ) due to uncertainties in energy data, as indicated by the difference in apparent consumption and measured consumption discussed above, and the other half (about $2 \%$ ) due to differences in heat values, carbon coefficients, oxidized/sequestered percentages of petroleum products, etc.

\section{Results}

Monthly data on $\mathrm{CO}_{2}$ emissions from oxidation of solid, gas and liquid fuels, as well as the total $\mathrm{CO}_{2}$ emissions, are shown in Fig. 1. The beginning of this record for total fossil-fuel consumption is limited by the length of the record of energy consumption from petroleum products, which extends back only to 1981 . Monthly records for coal and natural gas extend back to 1973. The numerical values for all fuels, back to 1981, are available at http://cdiac.esd.ornl.gov/trends/emis_mon/emis_mon_co2.html. All results are expressed in terms of the mass of contained carbon, recognizing that the carbon exists in the atmosphere as $\mathrm{CO}_{2}$.

The most obvious features of Fig. 1 are: (1) the annual cycle in emissions from natural gas, (2) the annual and semi-annual cycles in emissions from coal, (3) the lack of a clear annual cycle in emissions from liquid fuels and (4) the general upward trend in all four time-series shown. The semi-annual cycle for coal probably relates to increased use of electricity during winter, for additional lighting and indoor activities, and during summer, for air conditioning. Figure 2 shows that the amplitude of the annual cycle of emissions from all fuels does not increase through time, but rather appears to decrease-in spite of increases in population, number of populated buildings, number of vehicles, heating requirements, etc., and in the associated $\mathrm{CO}_{2}$ emissions. It further appears from Fig. 2 that summer emissions are increasing more rapidly than winter emissions, suggesting some changes in the annual pattern of energy use. The monthly data used to create Fig. 2 have been scaled so that each month represents $30.417 \mathrm{~d}$ (30.5 d for leap years) so that the seasonal patterns are not distorted by the varying lengths of the months.

Except for Fig. 2, the monthly emissions data presented here and on our web site are for the calendar month; that is, the data are not scaled to adjust for the number of days comprising each month. Scaling changes the monthly values by less than 2 per cent, except for February when the percentage change is around 8 per cent normally and 5 per cent in leap years. Thus, in the adjusted data, February values for petroleum are close to those of December and January, but if the unadjusted data are used, February values are often closer to those of the spring months. 




Year (tick nark corres ponds to January)
Fig 1. Estimates of monthly carbon emissions from consumption of fossil fuels in the US.

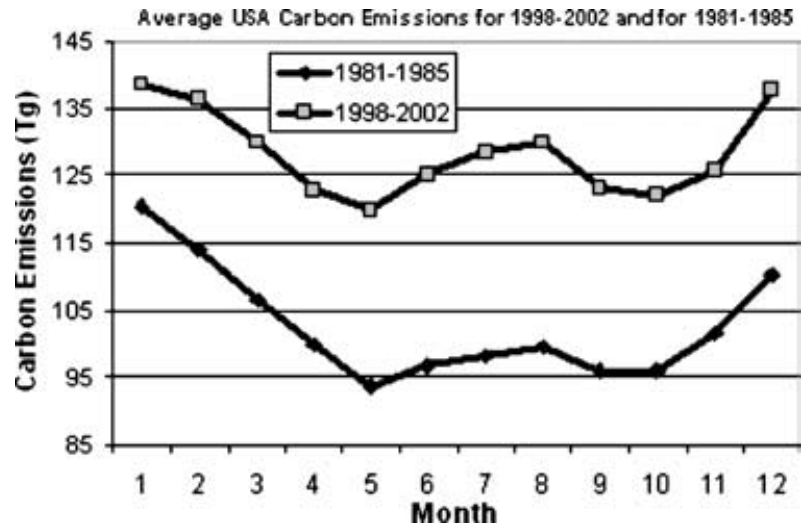

Fig 2. Five-year averages of monthly carbon emissions for early and recent periods, showing increased peaking during the summer.

\section{Comparison with other data}

In this section we first show that the emissions estimates introduced in this paper are generally consistent with results of previous work addressing only annual emissions. Where differences occur, they generally represent refinements and improvements incorporated into the estimates presented here. We then apply our findings to explain differences between our monthly estimates for the year 1982 and the estimates made, for that year only, by Rotty (1987).

\subsection{Comparison of total annual values}

Beginning in 1990, the US EPA has published estimates of annual $\mathrm{CO}_{2}$ emissions from fossil-fuel combustion and we have summed our monthly data in order to compare with the annual data from the EPA. Figure 3 includes a comparison of our annual totals with the annual totals reported by the EPA (2003). Because both of the data series are based on energy data directly from the US DOE/EIA, the annual totals differ by about $2 \%$ or less. Differences are due largely to differing computational schemes for

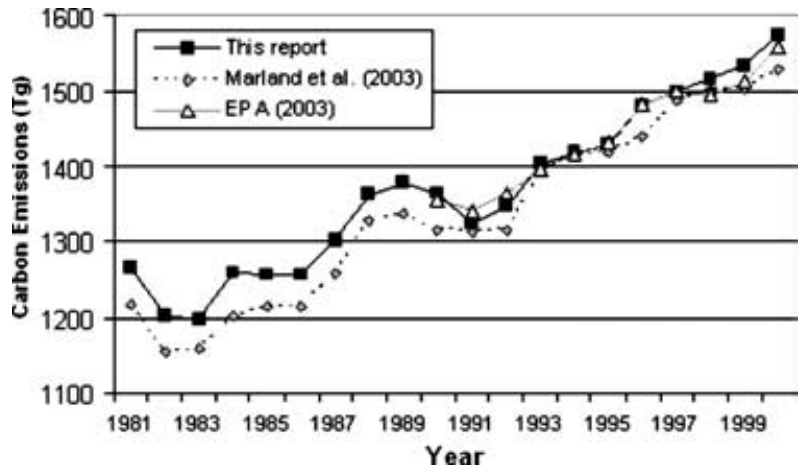

Fig 3. Comparison of the results of this paper with those of Marland et al. (2003) and of EPA (2003).

tracking fuel and non-fuel uses of individual petroleum products. There are also differences in the time at which the basic DOE/EIA data were used (these data series are revised periodically), so that two groups using the "same" database might actually be using different revisions of the same database.

Figure 3 also compares our estimates presented here with those of Marland et al. (2003). Although emissions values for solid fuels are essentially the same, those of Marland et al. (2003) are consistently lower for liquid and gaseous fuels. There are two factors largely responsible for these differences. First, our estimates account for the oxidation of some fraction of non-fuel petroleum products, e.g. naphthas and lubricants EPA (2003), while the estimates of Marland et al. (2003) account only for emissions from fossil fuels when used as fuels. Another reason for the higher estimates presented here, particularly for 1976 to 1991, is an apparent problem in the United Nations (UN) energy data base for natural gas, on which the emissions estimates of Marland et al. (2003) are based. Post-1976 UN accounting apparently involved some confusion of US conventions on "wet" gas (before natural gas liquids are separated out) and "dry" gas (after the liquid portion has been separated out) and the change in heating value that occurs during this "shrinkage". After 1991 


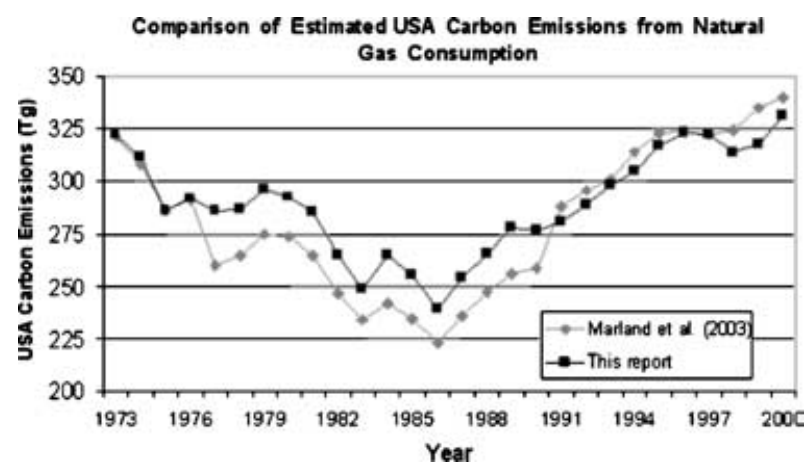

Fig 4. Comparison of the results of this paper for natural gas consumption with CDIAC (United Nations) data (Marland et al., 2003).

the problem was largely compensated by an accounting change in the calculation of "shrinkage" (see Fig. 4).

Note that the UN energy data are based on national reports, including those from the US, and should, in theory, be the same as those we obtained directly from the US DOE/EIA. However, the UN values are reported in different units and reflect differences in some calculated and estimated values. We have not always been able to do a precise mapping from US reported values (in volume or mass units) to UN reported values (in energy units), but starting with US tabulations we can get close to the UN reported values and can make some detailed comparisons.

In summary, there are four primary reasons that the numbers produced here differ from the numbers published previously by Marland et al. (2003):

(1) Estimates produced here are based on data directly from the US DOE/EIA whereas the earlier estimates are based on these same data, but as compiled and summed by the UN with slightly different categories, reporting dimensions and data structures.

(2) Estimates produced here are based on data for fuel "consumption" whereas earlier estimates are based on "apparent consumption".

(3) Estimates produced here have made allowance for oxidation of fossil fuel products even if those products are not used as a fuel, whereas earlier estimates are based only on fuel uses.

(4) Estimates produced here use country and fuel-specific (and sometimes year-specific) coefficients for converting fuel consumption values into $\mathrm{CO}_{2}$ emissions whereas the earlier numbers use global and time-averaged values.

Despite this array of differences, the two data sets differ by an average of $2.4 \%$ in their annual estimates of $\mathrm{CO}_{2}$ emissions from the US. We suggest that the data set of Marland et al. (2003) provides an appropriate and consistent measure for summing or comparing across countries and over long time periods, but that the current data set provides more accuracy and detail for looking at specifics within the US over the last two decades.

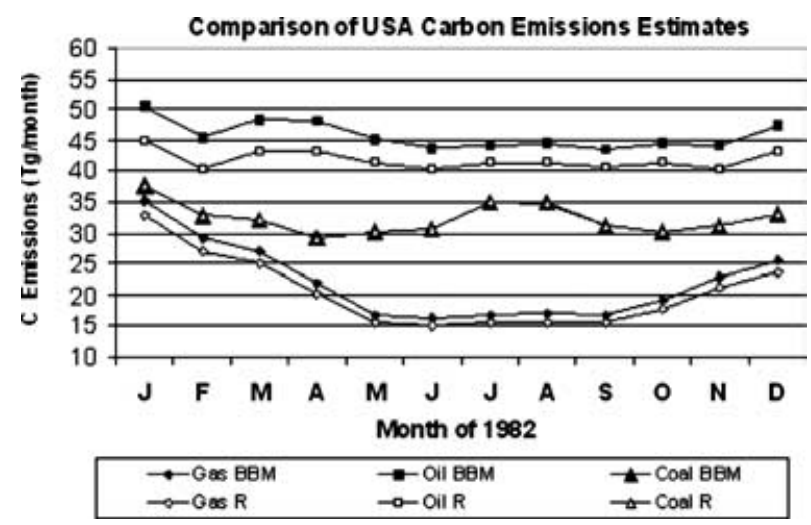

Fig 5. Comparison of our (BBM) estimates of carbon emissions from combustion of natural gas, oil, and coal in the US with similar emissions estimates published by Rotty (R) in 1987.

\subsection{Comparison of monthly estimates for the year 1982}

Almost 20 yr ago, Rotty (1987) began to address the problem of monthly emissions estimates. He allocated US annual carbon emissions for one year, 1982, to the 12 calendar months of that year, based on energy usage as reported by the DOE/EIA. Rotty's results are compared with ours in Fig. 5. Results for coal are almost exactly the same as ours, which was expected. Our results for the oxidation of petroleum products are higher, largely because we allowed for oxidation of some petroleum products not used as fuel. Our results for natural gas are about $8 \%$ higher than Rotty's; this difference can be attributed to the differences in accounting procedure for natural gas in the UN data set, as discussed above. Also, there have probably been some minor revisions within the energy data sets since 1987.

\section{Applications to monthly and seasonal studies}

The existence of monthly data on carbon emissions permits several useful types of investigation that would not be possible in the absence of such data. Here we present a few such applications. We begin with a discussion of the annual cycle in atmospheric $\mathrm{CO}_{2}$ concentration. We than present calculated values of the annual cycle of ${ }^{13} \mathrm{C}$ contained in the fossil-fuel carbon emissions. This will facilitate tracking these emissions on a seasonal basis. Finally, we examine the possibility that monthly emissions data can be used to identify spatial patterns of climate anomaly and trends in seasonally dependent appliances (e.g. air conditioners) that affect the emissions.

\subsection{Amplitude of the annual cycle of $\mathrm{CO}_{2}$ concentration}

The annual cycle of atmospheric $\mathrm{CO}_{2}$ concentration has been well documented with $46 \mathrm{yr}$ of data from the South Pole and Mauna Loa, and shorter time-series elsewhere. Carbon withdrawal from the atmosphere during the growing season 
overcomes carbon injection to the atmosphere from respiration and decay of organic matter from about May to September in the Northern Hemisphere and from about October to February in the Southern Hemisphere. The range (peak minus trough) of the annual cycle is about 15 parts per million by volume (ppmv) in high Northern Hemisphere latitudes, where seasons are pronounced and much of the surface area is occupied by boreal forest. In the Southern Hemisphere, where much of the land area is either at low latitudes and undergoes little seasonal influence or at polar latitudes where there is virtually no terrestrial biosphere to be seasonally influenced, the annual range of atmospheric $\mathrm{CO}_{2}$ concentration is only about 1-2 ppmv. The globally averaged range is greater than 1 per cent of the (approximately $375 \mathrm{ppmv}$ ) observed atmospheric concentration. For order-of magnitude estimates, a $1 \%$ range in the mass of atmospheric carbon would be about 7.3 Pg (IPCC, 2001), which is greater than the total fossil-fuel input of around $6 \mathrm{Pg} \mathrm{yr}^{-1}$ (Marland et al., 2003)

The amplitude of the annual cycle of atmospheric $\mathrm{CO}_{2}$ concentration has been increasing in recent years and the timing of the annual spring drawdown has been advancing. The increase in amplitude has been attributed to increasing assimilation and release of $\mathrm{CO}_{2}$ by land plants and the advance of the spring drawdown to climate warming (Keeling et al., 1996; Myneni et al., 1997). For North America, there is additional evidence of an earlier onset of spring (e.g. Blasing et al., 2003) and earlier blooming dates of plants (e.g. Cayan et al., 2001), and similar observations are accumulating elsewhere.

It is clear that the cycle of fossil-fuel use is not responsible for the annual cycle of $\mathrm{CO}_{2}$ concentration in the atmosphere. The annual global total of fossil-fuel input is less than the magnitude of the annual fluctuation. The biosphere is the only known influence large enough to account for the observed increase in annual amplitude of atmospheric $\mathrm{CO}_{2}$ concentration. Nonetheless, the fine-scale details of the fossil-fuel emissions will eventually be required to understand the details of the biospheric fluxes.

\subsection{Annual cycle of emitted $\delta^{13} \mathrm{C}$}

It is evident from Fig. 1 that a distinct annual pattern of carbon emissions exists for each of the three fuel types. Natural gas has an annual cycle that peaks in winter and is related to the heating of buildings; coal has a semi-annual cycle related to indoor energy use (including electricity for heating and lighting) in winter and air conditioning demands in summer; petroleum does not have any strong annual pattern that can be discerned from our data, although a slight winter peak is evident when our monthly values are scaled to represent months of equal length.

Because each fuel also has its own ${ }^{13} \mathrm{C}$ isotopic signature, and the relative proportions of the fuels oxidized vary in a distinct annual pattern, there will be an annual pattern of $\delta^{13} \mathrm{C}$ in the fossil-fuel $\mathrm{CO}_{2}$ emissions. For each month in our data set we multiplied the fraction of emitted carbon from each fuel type by the characteristic $\delta^{13} \mathrm{C}$ of its respective fuel and added the results. The characteristic $\delta^{13} \mathrm{C}$ values assigned to coal, oil and gas, respectively were $-24.1,-26.5$ and -44.0 parts per thousand (Andres et al., 2000). The values for coal and oil are the same as used by Tans (1981), but his value for gas was -41.0 .

Figure 6 shows our estimates of $\delta^{13} \mathrm{C}$ in carbon emitted from fossil-fuel combustion in the US and the numerical data can be found from http://cdiac.esd.ornl.gov/trends/ emis_mon/emis_mon_co2.html. This cycle clearly follows the annual cycle of natural gas combustion, having its largest negative value during winter. The amplitude (i.e. half the annual range) is about 1 part per thousand. These results may be useful in tracking emitted carbon by knowing the month or season when the carbon was emitted.

\subsection{Seasonal climate-carbon relationships}

Having monthly data on $\mathrm{CO}_{2}$ emissions, it is possible to examine potential relationships between seasonal climate and $\mathrm{CO}_{2}$

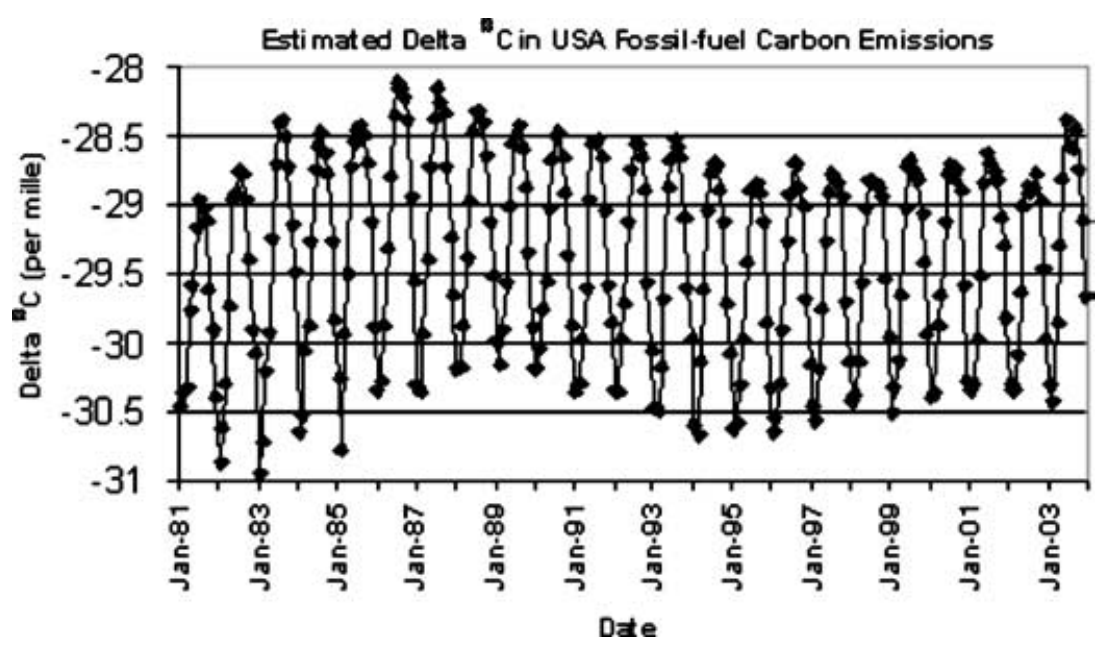

Fig 6. Annual cycle of the $\delta^{13} \mathrm{C}$ signature in US fossil-fuel carbon emissions. 


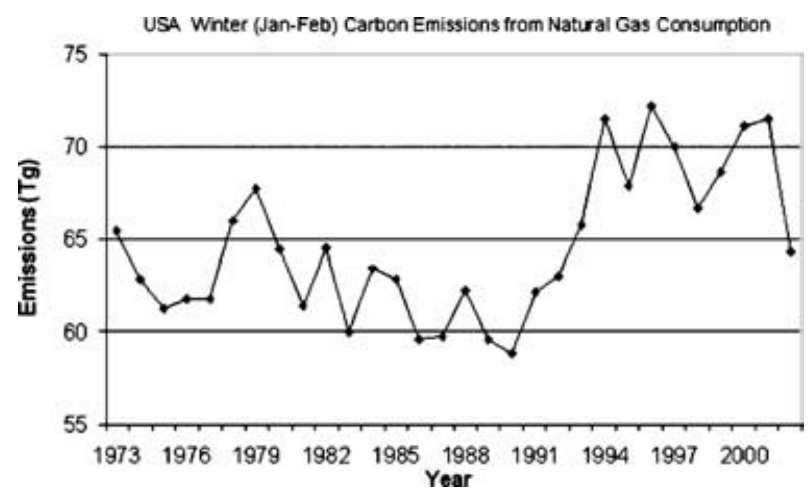

Fig 7. Winter carbon emissions from natural gas combustion in the US.

emissions, i.e. the potential for feedback from climate change to the impact of humans on the global carbon cycle. For example, a general global warming would be expected to decrease energy requirements for heating during winter but to increase energy requirements for air conditioning during summer. The winter relationship would be expected to show up best for natural gas, which shows an obvious seasonal cycle (Fig. 1), while in summer the relationship would be expected to show up best for coal, which is used to produce electricity for air conditioners and which seems to be showing a slight peaking tendency during the main cooling season (July-August) in recent years (Figs. 1 and 2) as discussed above.

5.3.1. Winter (January-February) heating. In the following subsections we suggest that monthly carbon emissions data can be useful in investigating relationships between seasonal climate and carbon emissions. Figure 7 shows $\mathrm{CO}_{2}$ emissions from winter (January plus February) natural gas consumption in the US from 1973 to 2002. Trends lasting for several years are present, often reflecting non-climatic effects (e.g. market conditions). Selection of an appropriate detrending procedure would be cumbersome, but it is still possible to use first derivatives to explore the possibility of relating carbon emissions from natural gas to climate anomalies. Therefore, we began by calculating year-to-year differences in the winter emissions estimates. We selected the five greatest year-to-year increases in carbon emissions for analysis. For each pair of successive years, the winter temperature pattern for the US during the leading year, for which emissions were low, was subtracted from the temperature pattern of the following winter, when emissions were much higher, to detect the underlying pattern of directional tendency for winter temperatures when US carbon emissions increase most prominently. Temperature data are from the reanalysis project described by Kalnay et al. (1996). The results (Fig. 8) suggest that the overriding directional tendency is for the largest year-to-year increases in carbon emissions from natural gas to be associated with corresponding decreases in winter temperatures in the heavily populated areas of the northeastern US, where winter temperatures are colder and more variable than along the (also heavily populated) southern California coast. However, the population distribution of the US allows for several spatial patterns of climate anomaly to be associated with high fuel use, and more detailed investigations of these phenomena, using the monthly emissions data, are likely to be productive.

5.3.2. Summer (July-August) cooling. As noted above, emerging summer peaks are evident in carbon emissions from coal and natural gas, which may be related to increased use of air conditioners. According to the DOE/EIA (EIA, 2000), the number of US housing units with central air conditioning rose from $23 \%$ in 1978 to $47 \%$ in 1997 . Moreover, during that same period,
Fig 8. Average winter temperature changes $\left({ }^{\circ} \mathrm{C}\right)$ from the previous year, corresponding to the five largest 1-yr increases in winter (January-February) carbon emissions from natural gas.

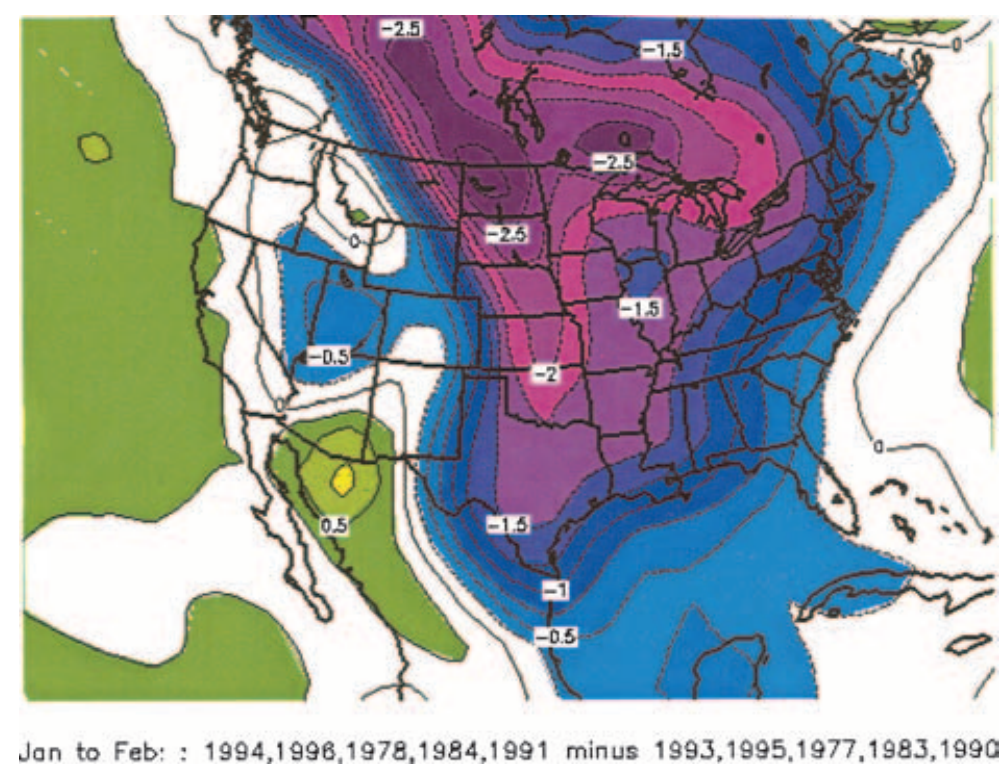


the amount of time a typical household used an air conditioner for was also increasing. Increases in air-conditioner efficiency appreciably countered these trends, so that while the number of homes with central air conditioners more than doubled and frequency/duration of use increased, the amount of electricity used for air conditioning in the residential sector increased by only about $35 \%$ of its 1978 value, from 0.31 to $0.42 \times 10^{15} \mathrm{Btu}$ (quads). This growth in energy use for air conditioning may at least partially explain the following features of Fig. 1: (1) the increasing magnitude of the summer peak in fossil-fuel carbon emissions from coal, (2) the emerging summer peak in $\mathrm{CO}_{2}$ emissions from combustion of natural gas and (3) the decreasing amplitude in total emissions from all fuels, because their rate of increase is greater during the summer trough than during the winter peak.

\section{Summary and conclusions}

Calculation of monthly $\mathrm{CO}_{2}$ emissions to the atmosphere from fossil-fuel consumption in the US, from 1981 to 2002, provides a data set that should be useful in examining details of the North American carbon cycle and in examining some of the interactions of the energy system and the climate system. The data show a clear annual pattern that generally resembles results obtained years ago by Rotty (1987), who, under the computational and data constraints of the time, made less rigorous calculations for year 1982 only. For the US, at least, the amplitude of the annual $\mathrm{CO}_{2}$ emissions cycle is decreasing, in contrast to the increasing amplitude of the annual cycle of atmospheric $\mathrm{CO}_{2}$ reported by Keeling et al. (1996). However, the biosphere is responsible for almost all of the amplitude of the annual cycle of atmospheric $\mathrm{CO}_{2}$ concentration, and the influence of fossil-fuel consumption is relatively very small. The changing proportions of emissions from coal, petroleum products and natural gas over the course of a year leads to an annual cycle of about $2 \%$ in the ${ }^{13} \mathrm{C}$ signature of the fossil-fuel $\mathrm{CO}_{2}$ emissions in the US. The highest and lowest values in the annual cycle of $\mathrm{CO}_{2}$ emissions may be influenced by seasonal temperature anomalies and increased use of air conditioning during the warmest months. Monthly data on fossil-fuel carbon emissions will allow the examination of such relationships.

\section{Acknowledgments}

This work was supported by US Department of Energy, Office of Science, Biological and Environmental Research Program. This project was supported by the Climate Change Research Division. Oak Ridge National Laboratory is managed by UTBattelle, LLC, for the US Department of Energy under contract DE-AC05-00OR22725. We especially thank Ms Julia Hutchins and her colleagues in the Energy Information Administration, US Department of Energy, for their support in providing the data and in clarifying exactly what they represent. The detailed supportive comments of two anonymous reviewers contributed appreciably to final version of this paper.

\section{References}

Andres, R. J., Marland, G., Boden, T. and Bischof, S. 2000. Carbon dioxide emissions from fossil fuel consumption and cement manufacture, 1751-1991, and an estimate of their isotopic composition and latitudinal distribution. In: The Carbon Cycle (eds.T. M. L. Wigley and D. S. Schimel). Cambridge University Press, Cambridge, 53-62.

Blasing, T. J., Scott, D. B. and Kaiser D. P. 2003. Evidence for recent changes in a surface-air warming singularity in late winter over central North America. Geophys. Res. Lett. 30(9), 1452, doi:10.1029/2002GL016807.

Cayan, D. R., Kammerdiener, S. A., Dettinger, M. D., Caprio, J. M. and Peterson, D. H. 2001. Changes in the onset of spring in the western United States. Bull. Am. Meteorol. Soc. 82, 399-415.

EIA (Energy Information Administration, US Department of Energy) 1995. Emissions of Greenhouse Gases in the United States: 19871994. DOE/EIA-0573(94). Office of Integrated Analysis and Forecasting, Washington DC.

EIA (Energy Information Administration, US Department of Energy) 2000. Trends in Residential Air-conditioning Usage from 1978 to 1997. http://www.eia.doe.gov/emeu/consumptionbriefs/recs/ actrends/recs_ac_trends.html (on 10 September 2003).

EIA (Energy Information Administration, US Department of Energy) 2002. Emissions of Greenhouse Gases in the United States: 2001. DOE/EIA-0573(2001). US Department of Energy, Washington, DC.

EIA (Energy Information Administration, US Department of Energy) 2003. Appendix A, Thermal conversion factors. Monthly Energy Review July, 157-166.

EPS (US Environmental Protection Agency) 2002. Inventory of U.S. Greenhouse Gas Emissions and Sinks: 1990-2000. EPA 430-R-02003. US Department of Energy, Washington, DC.

EPA (US Environmental Protection Agency) 2003. Inventory of U.S. Greenhouse Gas Emissions and Sinks: 1990-2001. EPA 430-R-03004. US Department of Energy, Washington, DC.

IPCC (Intergovernmental Panel on Climate Change) 1997. Greenhouse Gas Inventory Workbook: Revised 1996 IPCC Guidelines for National Greenhouse Gas Inventories, Volume 2. IPCC Technical Support Unit, Bracknell.

IPCC (Intergovernmental Panel on Climate Change) 2001. Climate Change 2001, The Scientific Basis. Contribution of Working Group I to the Third Assessment Report of the Intergovernmental Panel on Climate Change. Cambridge University Press, Cambridge, UK.

Kalnay, E., Kanamitsu, M., Kistler, R., Collins, W., Deaven, D. and coauthors, 1996. The NCEP/NCAR Reanalysis 40-year project. Bull. Am. Meteorol. Soc. 77, 437-471.

Keeling, C. D., Chin, J. F. S. and Whorf, T. P. 1996. Increased activity of northern vegetation inferred from atmospheric $\mathrm{CO}_{2}$ measurements. Nature 382, 146-149.

Keeling, C. D. and Whorf, T. P. 2003. Atmospheric $\mathrm{CO}_{2}$ records from sites in the SIO air sampling network. In: Trends, A Compendium of Data on Global Change, Carbon Dioxide Information Analysis 
Center, Oak Ridge National Laboratory, US Department of Energy, Oak Ridge, TN. http://cdiac.esd.ornl.gov/trends/co2/sio-keel.htm.

Marland, G., Boden, T. and Andres, R. J. 1995. Carbon dioxide emissions from fossil fuel burning: emissions coefficients and the global contribution of Eastern European countries. Idöjaras 99, 157-170.

Marland, G., Boden, T. A. and Andres, R. J. 2003. Global, regional, and national fossil fuel $\mathrm{CO}_{2}$ emissions. In: Online Trends: A Compendium of Data on Global Change. http://cdiac.ornl.trends/ emis/em_cont.html.

Marland, E. and Marland, G. 2002. The treatment of long-lived, carboncontaining products in inventories of carbon dioxide emissions to the atmosphere. Environ. Sci. Policy 6, 139-152.

Marland, G. and Rotty, R. M. 1984. Carbon dioxide emissions from fossil fuels: a procedure for estimation and results for 1950-1982. Tellus 36B, 232-261.

Myneni, R. B., Keeling, C. D., Tucker, C. J., Asrar, G. and Nemani, R. R. 1997. Increased plant growth in the northern high latitudes from 1981 to 1991. Nature 386, 698-702.
Rotty, R. M. 1987. Estimates of seasonal variation in fossil-fuel $\mathrm{CO}_{2}$ emissions. Tellus 39B, 184-202.

Sale, M. and Hadley, S. W. 2002. Estimating hydropower's contribution to the control of greenhouse gas emissions. Hydro Review, $\mathbf{X X I}(7)$, $47-50$.

Steele, L. P., Krummel P. B. and Langenfelds, R. L. 2002. Atmospheric $\mathrm{CO}_{2}$ concentrations from sites in the CSIRO Atmospheric Research GASLAB air sampling network (October 2002 version). In: Trends, A Compendium of Data on Global Change. Carbon Dioxide Information Analysis Center, Oak Ridge National Laboratory, US Department of Energy, Oak Ridge, TN. http://cdiac.esd.ornl. gov/trends/co2/csiro/csiro_gaslab.html

Tans, P. $1981 .{ }^{13} \mathrm{C} /{ }^{12} \mathrm{C}$ of industrial $\mathrm{CO}_{2}$. In: Carbon Cycle Modelling, SCOPE 16. John Wiley, Chichester, 127-129.

Wofsy, S. C. and Harris, R. C. 2002. The North American Carbon Pro$\operatorname{gram}(N A C P)$. Report of the NACP Committee of the US Interagency Carbon Cycle Science Program. US Global Change Research Program, Washington, DC (available at http://www.esig.ucar.edu/nacp/). 